\title{
Identity Processes in Collective Action Participation: Farmers' Identity and Farmers' Protest in the Netherlands and Spain
}

\author{
Bert Klandermans \\ Department of Social Psychology, Free University, Amsterdam
}

Jose Manuel Sabucedo and Mauro Rodriguez

Department of Social Psychology, University of Santiago de Compostela, Spain

Marga de Weerd

Regioplan, Education and Labormarket, Amsterdam

This study tested the assumption that a sense of collective identity stimulates participation in collective action. Contextual circumstances supposedly make a collective identity more salient and compel people to act as members of the group; protest participation is more likely among people with a strong collective identity. Group identification and participation in identity organizations were used as indicators of collective identity in a study of 248 farmers from Galicia (Spain) and 167 farmers from the Netherlands. The farmers were interviewed three times at intervals of 1 year. The longitudinal design also allowed a test of causality. A sense of collective identity appeared to stimulate preparedness to take part in farmers' protest. Action preparedness leads to action participation, which in turn appears to foster collective identity.

KEY WORDS: collective identity, identity strength, protest participation, social movements, collective action, longitudinal design, comparative research

In the past few years we have witnessed a growing interest in the role of identity processes in the dynamics of protest. In a way, this is not so surprising. After all, protest is usually defined as a form of collective behavior triggered by some perceived injustice done to groups that people identify with. Indeed, it is more surprising that it took so long for identity processes to become an integrated part of theory and research on political protest. 
In the social movement literature, the work on identity has remained predominantly theoretical. Empirical research, when it appeared, was mostly qualitative, with few attempts to actually measure identity. Social psychological research on collective identity, on the other hand, has always been more empirically and quantitatively oriented but has paid little attention to social movements and political protest, Reicher's work being an early exception (1984).

Recently, however, several social psychologists have begun to systematically investigate identity processes in the context of collective action. Kelly and Breinlinger (1996) looked into the role of collective identity in participation in the labor movement and the women's movement. Simon et al. (1998) studied the role of collective identity in participation in the gay movement and movements of the elderly. Mummendey, Klink, Mielke, Wenzel, and Blanz (1999) examined the role of group identification in the preference for collective action as a status management strategy among former East Germans. De Weerd and Klandermans (1999) looked at farmers' protest in the Netherlands, and Stürmer (2000) studied identity processes in the gay movement. These studies suggest that there is (in the words of Simon et al.) a dual pathway to social movement participation —one guided by instrumental reasoning about the costs and benefits of participation, the other guided by processes of identification.

There is evidence that identity processes have both an indirect and a direct effect on protest participation (Stürmer, 2000). An indirect effect arises because collective identity influences instrumental reasoning such that taking a "free ride" becomes less attractive. Indeed, collective identity is a way to overcome the social dilemma built into the dynamics of movement participation (Klandermans, 2000). High levels of group identification increase the costs of defection and the benefits of cooperation. In other words, collective identity has an impact on the instrumental pathway to protest participation. A direct effect arises because collective identity creates a shortcut to participation. People participate not so much because of the outcomes associated with participation but because they identify with the other participants. Stürmer advanced the hypothesis that participation generated by the identity pathway is a form of automatic behavior, whereas participation generated by the instrumental pathway is a form of reasoned action.

But what about the opposite causal link, that is, the influence of social movement participation on identity? Anyone who has ever taken part in or witnessed an episode of collective action recognizes that collective action reinforces collective identity. The seminal work of Reicher has documented this causal link time and again (Drury, Reicher, \& Scott, 1999; Reicher, 1984, 1996). Cross-sectional studies are not able to disentangle causality, but because our study had a panel design, we can shed some light on the question of the causal direction of the link between identity and participation in collective action. Here, we take the instrumental pathway for granted and concentrate on identity processes in the context of participation in collective action-not so much because the instrumental pathway is unimportant (see Klandermans, 1997, for a discussion), but because we want to clarify some matters with regard to the identity pathway. 


\section{Collective Identity}

Simon $(1998,1999)$ succinctly described identity as a place in society. People occupy many different places in society: student, unemployed, housewife, soccer player, politician, farmer, and so on. Some of those places are exclusive, occupied by only a small number of people. The members of a soccer team are an example. Others are inclusive, encompassing large numbers of people, such as "Europeans." Some places are mutually exclusive, such as male/female or employed/unemployed; some are nested, for example, French, Dutch, or German versus European; and some are cross-cutting, such as female and student (Hornsey \& Hogg, in press; Turner, 1999).

Personal and collective identity. All these different roles and positions that a person occupies form his personal identity. At the same time, every place a person occupies is shared with other people. One is not the only professor of social psychology, nor the only Dutch or the only European. We share these identities with other people-a fact that turns them into collective identities. Thus, a collective identity is a place shared with other people. This implies that personal identity is always collective identity at the same time. Personal identity is general, referring to a variety of places in society, whereas collective identity is always specific, referring to a specific place.

Salient collective identity. Most of the time, collective identities remain latent. Self-categorization theory hypothesizes that, depending on contextual circumstances, an individual may act as a unique person (displaying personal identity) or as a member of a specific group (displaying one of many collective identities) (Turner, 1999; Turner, Hogg, Oakes, Reicher, \& Wetherell, 1987). Contextual factors may bring personal or collective identity to the fore. Obviously, this is often not a matter of free choice. Circumstances may force a collective identity into awareness whether people like it or not. Recent notable examples are Yugoslavia and South Africa, and even more dramatic examples have occurred throughout human history. But collective identities can also become significant in less extreme circumstances. Consider, for example, the possible effect of an announcement that a waste incinerator is planned next to a neighborhood. Chances are that within a very short time, the collective identity of the residents of that neighborhood will become salient. Identities are, however, not always imposed on people-and even when they are, people can choose to stay aloof.

Identity strength. Self-categorization theory proposes that people who identify more with a given social category are more prepared to use that category in their self-definition. Identification with a group makes people more prepared to act as members of that group (Turner, 1999). This assertion refers, of course, to identity strength. In her review of social identity theory, Huddy (2001) observed that the social identity literature tends to neglect that real-world identities vary in strength. But, she argued, the relative strength of identification with a group may make a real difference, especially in political contexts. Moreover, she suggested, strong 
identities are less affected by context. Following this reasoning, we may expect that strong identities make it more likely that people act on behalf of their group.

Components of collective identity. Collective identity, as it is defined here, is related to social identity (Tajfel, 1981; Tajfel \& Turner, 1986). Social identity theorists suggest that social identity has three components: a cognitive component that refers to the process of categorization, an evaluative component that refers to the assessment of the group's position relative to that of other groups, and an affective component that refers to the degree of attachment to the group or category. Group identification is akin to the affective component of social identity. Laboratory experiments reveal that the affective component has the largest impact on someone's behavior (Ellemers, 1993).

We suggest the addition of a fourth, behavioral component: participation in identity organizations. In a discussion of social identity and political involvement, Andrews (1991) made the distinction between voluntary and involuntary group membership. Gender, age, race, nationality, and social class are examples of involuntary groups; the awareness of belonging to such a group need not evoke any positive or negative feelings. Examples of voluntary groups are women's organizations or unions of the elderly. Membership in such identity organizations is self-chosen, and such a choice can emphasize one's involuntary group membership — such as, for example, a Surinam in the Netherlands who becomes a member of a Surinam association. Conversely, choosing not to belong can be an act of denying one's involuntary group membership-for example, an older person who refuses to become a member of a union of the elderly. Thus, membership in an identity organization underscores group identification.

Politicized collective identity. Awareness of a collective identity does not necessarily make that identity politically relevant. Yet we hold that for people to become involved in political protest on behalf of a group, the collective identity of that group must be politicized. Simon and Klandermans (2001) have attempted to develop a theoretical model for the politicization of collective identity. According to these authors, "people evince politicized collective identity to the extent that they engage as self-conscious group members in a power struggle on behalf of their group knowing that it is the wider, more inclusive societal context in which this struggle has to be fought out" (p. 319). They suggested that a collective identity as a member of a movement (e.g., the gay movement) is more politicized than a collective identity as a member of the social category the movement draws from (e.g., gay men). Therefore, in the context of the four components of social identity outlined above, we assume that the strength of the behavioral component of collective identity is the most indicative of the level of politicization of a collective identity.

In this paper we concentrate on the affective and behavioral components of collective identity, that is, on group identification and on membership in an identity organization. 


\section{Collective Identity and the Dynamics of Protest}

Identity and protest. The basic hypothesis regarding collective identity and protest is fairly straightforward: A strong identification with a group makes participation in political protest on behalf of that group more likely. The available empirical evidence overwhelmingly supports this assumption (de Weerd \& Klandermans, 1999; Kelly \& Breinlinger, 1996; Simon et al., 1998; Stürmer, 2000). Each of these studies suggests some further specifications. Kelly and Breinlinger observed a moderating role of identification. They suggested that when group identification is weak, the instrumental route to participation is of more importance than when group identification is strong. Simon et al. showed that identification with the members of a movement organization has more impact on protest participation than does identification with the general category the movement appeals to. This finding corroborates that of de Weerd and Klandermans, who showed that membership in identity organizations affects protest participation more strongly than does identification with the group in general. Stürmer, finally, observed that of the two dimensions of collective identity he distinguished-importance and evaluation-it is predominantly the former that is linked to protest participation. In other words, what matters is how important group membership is to someone's self-image, rather than how the group is evaluated by self and others. Moreover, Stürmer found that collective identity could predict not only protest participation, but also willingness to serve as a volunteer for a movement organization.

Causality. Some of these studies are longitudinal and therefore provide data regarding the direction of causality, but the results are inconclusive. Whereas Stürmer's data suggest that it is collective identity that stimulates participation rather than participation that fosters collective identity, de Weerd and Klandermans' results suggest a more complex story. These authors found that group identification (the affective component of collective identity) affects action preparedness, which in turn affects action participation. The behavioral component (membership in an identity organization), however, seems to work in both directions. That is, membership stimulates participation and participation stimulates membership. Reicher and his colleagues (Drury et al., 1999; Reicher, 1984, 1996) have demonstrated repeatedly that participation in collective action strengthens identification with the group, but these are studies of participants only; hence, it is difficult to decide whether it was action participation that made the difference.

Comparing farmers in the Netherlands and Spain. In a way, the study described below can be conceived as a quasi-experiment. We compare farmers in Galicia (the most northwestern province of Spain) and the Netherlands. As far as collective identity and the dynamics of protest are concerned, such a comparison makes sense. Agriculture in the Netherlands more than in Spain has been the subject of political intervention and regulation. In response, farmers in the Netherlands established professional organizations that have since evolved into a powerful agricultural lobby. Agriculture became one of the best organized sectors of the Dutch economy. 
The establishment of the European Community has reinforced the situation; Dutch and European politics turned farmers in the Netherlands into a group with common interests and opponents. In Spain and certainly in Galicia, farmers are weakly organized relative to those in the Netherlands; moreover, Spain entered the European Community more than 20 years later. Therefore, we expect a stronger sense of collective identity among Dutch farmers than among Galician farmers. On the other hand, farmers' organizations in Spain are more politicized than their counterparts in the Netherlands. Spanish farmers' organizations are branches of political parties, whereas Dutch farmers' organizations are professional organizations to which almost any farmer can belong. Therefore, we expect a stronger effect of membership in farmers' organizations on protest participation in Galicia than in the Netherlands.

\section{Hypotheses}

The reasoning thus far can be summarized in several hypotheses that will guide our examination of the results: The more farmers identify with other farmers, the more likely they will engage in farmers' protest. Farmers who belong to farmers' organizations are more likely to take part in farmers' protest than are farmers who do not belong to such organizations. Dutch farmers are more likely to identify with other farmers and to belong to a farmers' organization, and therefore they are more likely than Galician farmers to engage in farmers' protest. Galician farmers who belong to a farmers' organization are more likely to engage in farmers' protest than are Dutch farmers who belong to a farmers' organization.

Because the literature is inconclusive in regard to the causal relationship between collective identity and protest participation, we defined causality as a matter to explore.

\section{Method}

\section{Research Design and Participants}

The research reported here is part of a larger study on farmers' protest. $^{1}$ In the context of that study we interviewed 167 Dutch farmers and 248 Galician farmers three times, namely in the winter of 1993-1994 (henceforth 1993-94), winter 1995 (1995/1), and fall 1995 (1995/2). During those 2 years, several agricultural measures to be taken by the government or the European Union were imminent, varying in impact on the agricultural sector. The study was designed to investigate farmers' responses to these measures. We have chosen the Netherlands and Galicia because

\footnotetext{
${ }^{1}$ In addition to the identity factors discussed in this paper, the farmers' protest study concerned variables such as relative deprivation, feelings of injustice, trust in government, the costs and benefits of participation, evaluation of the agricultural policy of the European Union, and so on. In the Dutch part of the study, identity factors appeared to have a unique contribution to the explanation of protest participation (de Weerd, 1999). In this paper we concentrate on that contribution.
} 
they are similar as far as agricultural products are concerned but opposites as far as agricultural development is concerned. In both countries the same kinds of farmers were involved, mainly from dairy, arable, and mixed farms, but on modern and large-scale enterprises in the Netherlands and old-fashioned and small-scale farms in Galicia. Trained interviewers at the respondents' homes conducted face-to-face, computer-assisted interviews. The interviews lasted 45 minutes on average.

The participants in our interviews came from samples drawn from selected farming communities. The criteria used to select communities were (1) a large enough population of farmers, and (2) an average size of farms in the community similar to the national average (Netherlands) or the provincial average (Galicia). All farmers from the selected communities were asked for their cooperation. This paper is based on those farmers in the two countries for whom we had complete information. ${ }^{2}$ Obviously, the samples were not random samples of the farmers in Galicia or the Netherlands, nor are they necessarily representative. ${ }^{3}$ For our panel design this is not a problem, as we were interested in changes over time and the group served as its own standard. The mean age of the respondents in the two samples was about the same: 46 years in the Netherlands and 49 in Galicia. Level of education and size of farm illustrate the opposite character of the two areas. In the Netherlands, the majority of the respondents (70\%) completed secondary or higher agricultural education, and most farmers had average- to large-size farms (70.7\%). In Galicia we found the opposite: $90 \%$ of our respondents had only primary education, and $77 \%$ had small farms.

\section{Measures}

Group identification was assessed by asking respondents to agree or disagree with the statement "I feel little commitment to other farmers."4

Membership in a farmers' organization was assessed by asking respondents whether they were members; if so, we asked them to indicate which of seven possible activities they engaged in. The answers to these questions were combined into a single measure of participation in farmers' organizations, generating a score of 0 (not a member), 1 (member), or 2 (active member).

2 Response rates are not very informative in this context. First, different sampling procedures were used in the two countries. In Spain, interviewers were instructed to conduct a fixed number of interviews in a community. They stopped once that number was reached. No record was kept of refusal or absences. In the Netherlands, all the farmers in a community were approached. On average $38 \%$ of the farmers agreed to participate. In both countries, these procedures resulted in the agreed-upon sample of 360 in the first wave. Second, we only used those interviews for the panel design where the same person was interviewed all the time. Third, in the Netherlands some 30 identification numbers were lost, so we were not able to connect the three interviews.

3 On the few comparisons we were able to make (age and size of farm), our sample did not differ significantly from the population, but these are, of course, only two indicators.

4 We used several other measures of group identification. The correlations with these other measures ranged from .19 to .35 , but this simple question turned out to be the best predictor of action preparedness (see de Weerd \& Klandermans, 1999). 
Protest participation was registered in two different ways. We assessed respondents' preparedness to take part in four forms of collective action that were part of the action repertoire of farmers in those days-demonstrations, blockades, symbolic actions (such as dumping dung on the doorsteps of the ministry of agriculture), and refusal to pay taxes. For each of these action forms, we asked whether they would participate if they were to disagree completely with an agricultural measure or with agricultural policy in general. For each action form, respondents could indicate on a scale ranging from 1 (not at all prepared) to 5 (very much prepared) to what extent they were prepared to participate. The answers to these questions were taken together into a scale of action preparedness ranging from 1 (not at all prepared to take part in any form of collective action) to 5 (very much prepared to take part in all forms selected). Cronbach's $\alpha$ of the scale at the three points in time was satisfactory $(.75, .74$, and .75$)$. In addition, we asked in the first interview whether respondents "took part in any collective action directed at agricultural measures or policy in the past." In the second and third interview we asked them whether they had "taken part in any collective action [directed at agricultural measures or policy] since the previous interview." The answers to these questions were used as a measure of action participation.

Political identification was measured on a self-assessment scale from 1 (left) to 10 (right). Demographic data were also collected, such as age, education, size of farm, and type of farm.

\section{Results}

Table I presents a comparison of collective identity, action preparedness, and action participation in the two countries. Proportions of the samples that took part in collective action are shown, as are the means for action preparedness, group identification, and participation in identity organizations. The data confirm our expectations. Relative to Galician farmers, Dutch farmers identify more with other farmers (main effect country: $F=64.98, \mathrm{df}=1, p<.0001$ ) and more often belong to a farmers' organization (main effect country: $F=524.57 \mathrm{df}=1, p<.0001$ ). The

Table I. Action Participation and Action Preparedness

\begin{tabular}{lcccccc}
\hline & \multicolumn{3}{c}{ Galicia } & \multicolumn{3}{c}{ Netherlands } \\
& $1993-94$ & $1995 / 1$ & $1995 / 2$ & $1993-94$ & $1995 / 1$ & $1995 / 2$ \\
\hline Action participation & $37.3 \%^{\mathrm{a}}$ & $2.8 \%^{\mathrm{b}}$ & $2.0 \%^{\mathrm{b}}$ & $86.8 \%^{\mathrm{a}}$ & $11.4 \%^{\mathrm{b}}$ & $17.4 \%^{\mathrm{b}}$ \\
Action preparedness $^{\mathrm{c}}$ & 2.59 & 2.41 & 2.50 & 2.84 & 2.75 & 2.80 \\
Identification with farmers $^{\mathrm{d}}$ & 1.77 & - & 1.66 & 1.95 & - & 1.94 \\
$\begin{array}{l}\text { Participation in farmers } \\
\quad \text { organization }\end{array}$ & 0.19 & 0.17 & 0.19 & 1.11 & 1.08 & 1.04 \\
\hline
\end{tabular}

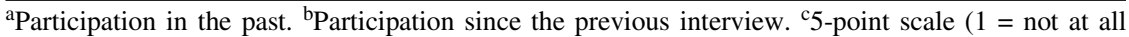
prepared, $5=$ very much prepared). ${ }^{\mathrm{d}} 1=$ no identification, $2=$ identification. ${ }^{\mathrm{e}} 0=$ not member, $1=$ member, 2 = active member. 
differences on the behavioral dimension of collective identity are especially impressive.

Together, these results suggest that collective identity as a farmer is more salient in the Netherlands than in Galicia. This led us to assume that Dutch farmers are more likely than Galician farmers to act on behalf of their group. In line with this theoretical reasoning, action preparedness (main effect country: $F=11.21$, df $=1, p=.001)$ and participation $\left(\chi^{2}\right.$ s, 1993-94, 92.04; 1995/1, 12.44; 1995/2, 31.25 ; df $=1$, all $p s<.0001$ ) are indeed higher among Dutch farmers. Overall, this pattern is fairly stable over time.

Although these results are in line with our expectations, they do not necessarily prove that it is identity processes that generate the differences in protest preparedness and participation. We therefore ran a series of regression analyses and analyses of variance (ANOVAs) and conducted cross-lagged analyses exploiting our longitudinal design.

\section{Predicting Protest Participation}

We begin our exercise with participation in protest in the year since the previous interview. Tables II and III present the outcomes of a series of logistic regression analyses, with participation in the next year as the dependent variable. The models 3 and 4 test whether identity processes add to the variance already explained by country and action preparedness (model 1 and 2).

The results are fairly straightforward. In both years, action participation is predicted by action preparedness in the previous interview. Identification with other farmers does not play a role. Participation in farmers' organizations as assessed in the previous interview is marginally significant (just below .05 in Table II and just above .05 in Table III). In 1995/2, participation in collective action since the previous interviews adds as well. In turn, participation between 1993-94 and $1995 / 1$ is predominantly predicted by action preparedness as measured in the previous interview. In Table III we added "type of farm" as a control variable

Table II. Predicting Protest Participation Between 1993-94 and 1995/1: Logistic Regression Analyses

\begin{tabular}{lcccc}
\hline & Model 1 & Model 2 & Model 3 & Model 4 \\
\hline Country (Netherlands = 2) & $1.49(.45)^{* *}$ & $1.36(.46)^{* *}$ & $1.49(.48)^{* *}$ & $.86(.58)$ \\
Action preparedness in 1993-94 & & $.78(.23)^{* * *}$ & $.87(.24)^{* * *}$ & $.78(.24)^{* *}$ \\
Identification with farmers in 1993-94 & & & $-1.07(.72)$ & $-1.22(.73)$ \\
Participation in farmers' organization & & & & \\
$\quad$ in 1993-94 & & & & $.79(.40)^{*}$ \\
-2 log likelihood & 182.09 & 168.85 & 166.93 & 163.08 \\
Improvement & $12.29 * * *$ & $13.25^{* * *}$ & 1.92 & $3.85^{*}$ \\
\hline
\end{tabular}

Note. The entries are unstandardized regression coefficients for an equation in which all variables are entered simultaneously; standard errors are in parentheses.

$* p<.05, * * p<.01, * * * p<.001$. 
Table III. Predicting Protest Participation Between 1995/1 and 1995/2: Logistic Regression Analyses

\begin{tabular}{|c|c|c|c|c|}
\hline & Model 1 & Model 2 & Model 3 & Model 4 \\
\hline Country $($ Netherlands $=2)$ & $2.68(.50) * * *$ & $2.99(.55)^{* * *}$ & $2.62(.62)^{* * *}$ & $2.60(.63)^{* * *}$ \\
\hline Type of farm (no manure & & & & \\
\hline problem $=0$ ) & $1.74(.56)^{* *}$ & $2.06(.60)^{* * *}$ & $2.04(.61)^{* * *}$ & $2.07(.62)^{* * *}$ \\
\hline Action preparedness in $1995 / 1$ & & $1.35(.28)^{* * *}$ & $1.33(.29)^{* * *}$ & $1.21(.29)^{* * *}$ \\
\hline $\begin{array}{l}\text { Participation in farmers' } \\
\text { organization in 1993-94 }\end{array}$ & & & $.48(.38)$ & $.35(.38)$ \\
\hline $\begin{array}{l}\text { Identification with farmers } \\
\text { in 1993-94 }\end{array}$ & & & $-.04(1.10)$ & $.25(1.13)$ \\
\hline $\begin{array}{l}\text { Action participation between } \\
1993-94 \text { and 1995/1 }\end{array}$ & & & & $1.27(.57)^{*}$ \\
\hline-2 log likelihood & 189.98 & 153.77 & 152.12 & 147.22 \\
\hline Improvement & $45.29 * * *$ & $36.21 * * *$ & 1.65 & 1.00 \\
\hline
\end{tabular}

Note. The entries are unstandardized regression coefficients for an equation in which all variables are entered simultaneously; standard errors are in parentheses.

$* p<.05, * * p<.01, * * * p<.001$.

because in the Netherlands most protest in the previous year was related to the manure regulation that the Dutch government imposed on the sector. Manure regulation is irrelevant for parts of the agricultural sector, and one would expect only those farmers to participate who are indeed affected by that regulation. The findings with regard to participation seem to run counter to our expectations. They suggest that the influence (if any) of collective identity on protest participation runs through action preparedness. We return to this topic below.

Obviously, differences in action preparedness do not fully explain the differences in participation between the two countries. In itself, this is hardly surprising. Action preparedness, as we measured it, concerns a general tendency to take part in collective action if required by circumstances. It is a propensity to act that materializes only if the opportunity arises. In the Netherlands, this occurred in the last year of our study in response to the manure regulation. Similarly, in Galicia there were quite a few farmers who would have been prepared to take part in collective action, had there been any. Action participation is not only dependent on people's readiness to participate (the demand side of participation) but also on the opportunities to participate offered to them (the supply side of participation).

\section{Predicting Action Preparedness}

Identity processes appear to have little direct influence on action participation. This is not to say that identity has no influence at all, but it may imply that identity processes work through action preparedness. Our next step, then, is to explore whether identity processes have an impact on action preparedness. Tables IV to VI present the results of regression analyses [ordinary least squares (OLS)] with action 
Table IV. Predicting Action Preparedness in 1993-94: Regression Analyses (OLS)

\begin{tabular}{|c|c|c|c|c|}
\hline & \multirow[t]{2}{*}{$r$} & \multicolumn{3}{|c|}{$\beta$} \\
\hline & & Model 1 & Model 2 & Model 3 \\
\hline Country (Netherlands $=2$ ) & .12 & $.12 *$ & .03 & $-.15^{*}$ \\
\hline Identification with farmers in 1993-94 & .37 & & $.36^{* *}$ & $.33 * *$ \\
\hline Participation in farmers' organization in 1993-94 & .25 & & & $.27 * *$ \\
\hline$R^{2}$ & & .01 & .13 & .17 \\
\hline
\end{tabular}

Table V. Predicting Action Preparedness in 1995/1: Regression Analyses (OLS)

\begin{tabular}{|c|c|c|c|c|c|}
\hline & \multirow[t]{2}{*}{$r$} & \multicolumn{4}{|c|}{$\beta$} \\
\hline & & Model 1 & Model 2 & Model 3 & Model 4 \\
\hline Country (Netherlands $=2$ ) & .15 & $.14^{* *}$ & .09 & $-.14^{*}$ & -.07 \\
\hline Identification with farmers in 1993-94 & .27 & & $.23 * * *$ & $.21 * * *$ & .04 \\
\hline $\begin{array}{l}\text { Participation in farmers' organization } \\
\text { in 1993-94 }\end{array}$ & .31 & & & $.34 * * *$ & $.18 * *$ \\
\hline $\begin{array}{l}\text { Action participation between } 1993 \\
\text { and 1995/1 }\end{array}$ & .23 & & & & $.10 * *$ \\
\hline Action preparedness in 1993-94 & .60 & & & & $.53 * * *$ \\
\hline$R^{2}$ & & .02 & .07 & .14 & .39 \\
\hline
\end{tabular}

Table VI. Predicting Action Preparedness in 1995/2: Regression Analyses (OLS)

\begin{tabular}{|c|c|c|c|c|c|}
\hline & \multirow[t]{2}{*}{$r$} & \multicolumn{4}{|c|}{$\beta$} \\
\hline & & Model 1 & Model 2 & Model 3 & Model 4 \\
\hline Country (Netherlands $=2$ ) & .14 & $.14 * *$ & .09 & $-.12 * *$ & -.06 \\
\hline Identification with farmers in 1993-94 & .28 & & $.23 * * *$ & $.21 * * *$ & .08 \\
\hline $\begin{array}{l}\text { Participation in farmers' organization } \\
\text { in 1993-94 }\end{array}$ & .13 & & & $.29 * * *$ & $.12 *$ \\
\hline $\begin{array}{l}\text { Action participation between } 1995 / 1 \\
\text { and } 1995 / 2\end{array}$ & .26 & & & & $.13 * *$ \\
\hline $\begin{array}{l}\text { Action participation between } 1993 \\
\text { and 1995/1 }\end{array}$ & .27 & & & & -.04 \\
\hline Action preparedness in $1995 / 1$ & .51 & & & & $.35 * * *$ \\
\hline Action preparedness in 1993-94 & .43 & & & & $.15^{* *}$ \\
\hline$R^{2}$ & & .02 & .07 & .12 & .32 \\
\hline
\end{tabular}

preparedness in the consecutive interviews as the dependent variable. The influence of identity processes in the generation of action preparedness is tested in models 2 and 3; the impact of country is assessed in model 1. In Tables V and VI, levels of identification and participation in identity organizations in 1993-94 are used to predict action preparedness in 1995/1 and 1995/2. 
Obviously, identity processes $d o$ have a significant influence on action preparedness. Inclusion of identification with other farmers and participation in farmers' organizations increases the variance explained from $1 \%$ to $17 \%$ in Table IV, from $2 \%$ to $14 \%$ in Table V, and from $2 \%$ to $12 \%$ in Table VI. In other words, almost 2 years later identity strength as assessed in 1993-94 continues to predict preparedness to participate in collective action. Model 4 in Tables V and VI suggests that the influence of identity is mediated by action preparedness. In model 4, action preparedness and participation in the previous waves were entered in the equation. Once these variables are taken into account, identity processes lose much of their direct influence. This is predominantly due to the impact of action preparedness. Interestingly, unlike identification with other farmers, participation in farmers' organizations continues to have a significant direct impact on action preparedness beyond its indirect influence via action preparedness in the previous interview.

However, the most interesting result in the tables is the changing sign of the coefficient for country in model 3. Each of the three tables reveals in model $1 \mathrm{a}$ significant positive $B$ for country, which means that action preparedness in the Netherlands is higher than in Galicia, a finding that was already apparent in Table I. Then, in model 2-where we entered identification with other farmers- the variance explained by country is reduced and no longer significant. But in model 3-after we enter participation in farmers' organizations-country not only contributes significantly again, but the sign of the $B$ turns negative. Model 1 indicates that farmers in the Netherlands are more prepared to take part in farmers' protest. Model 2 reveals that this is predominantly because Dutch farmers identify more with other farmers than Galician farmers do. Model 3, however, reveals that once we control for participation in farmers' organizations, farmers in Galicia are more prepared to take part in protest than are farmers in the Netherlands.

Table VII further specifies this finding. This table presents the results of two $2 \times 2$ ANOVAs with action preparedness in 1993-94 as the dependent variable, and country and identification and participation in farmers' organizations, respectively, as the factors. Obviously, once we control for level of identification, the differences in action preparedness between the two countries

Table VII. Action Preparedness in 1993 by Identification and Participation in Farmers' Organizations: Means

\begin{tabular}{lcccc} 
& \multicolumn{2}{c}{ Identification with farmers } & \multicolumn{2}{c}{ Participation in farmers' organizations } \\
& No & Yes & No & Yes \\
\hline Galicia & $1.77(0.89)$ & $2.83(1.00)$ & $2.42(1.04)$ & $3.32(0.88)$ \\
Netherlands & $2.00(0.84)$ & $2.89(1.02)$ & $2.62(0.78)$ & $2.86(1.06)$ \\
\hline
\end{tabular}

Note. Standard deviations are in parentheses.

${ }^{a}$ Main effect country: n.s.; main effect identification: $F=27.73$, $\mathrm{df}=1, p<.0001$; interaction: n.s.

${ }^{b}$ Main effect country: n.s.; main effect participation in organizations: $F=13.46$, df $=1, p<.001$; interaction: $F=4.34$, df $=1, p<.05$. 
are no longer significant. We found a significant main effect only for identification $(F=27.73, \mathrm{df}=1, p<.001)$. This means that farmers in Galicia are less prepared to take part in protest because they identify less with other farmers. If we control for the behavioral component of collective identity, the difference in action preparedness is no longer significant either, but the picture changes qualitatively. Galician farmers who participate in farmers' organizations are more prepared to participate in collective action than are Dutch farmers who participate in farmers' organizations. Those who do not participate have the same level of action preparedness in the two countries. In other words, if more Galician farmers were to participate in farmers' organizations, action preparedness in Galicia might have been higher than that in the Netherlands. We assumed that this was the case because farmers' organizations in Spain are more politicized, and thus being a member of a farmers' organization indicates a more politicized collective identity than being a member of such an organization in the Netherlands. To check this assumption, we computed correlations of participation in farmers' organizations and political identification. Indeed, the two were significantly correlated in Galicia (Pearson $r,-.17$ ), which means that members of farmers' organizations are more left-oriented than non-members, whereas in the Netherlands the two are virtually unrelated (Pearson $r,-.01$ ).

\section{Causality}

Collective identity seems to foster participation in collective action. Both identification with other farmers and participation in a farmers' organization stimulate action preparedness, which in turn stimulates action participation. We are not the first to make this observation, but few studies show that indicators of collective identity are able to predict action preparedness 2 years later. Because we have longitudinal data, we are also able to further investigate the causal direction of the link between collective identity and action participation. Table VIII provides the results of four regression analyses: the first two of the indicators of collective identity at $T_{1}$ (time 1) with action preparedness at $T_{3}$, and of the same indicators at $T_{3}$ with action preparedness at $T_{1}$; the second two of the indicators of collective identity at $T_{1}$ with action participation at $T_{3}$, and of the same indicators at $T_{3}$ with action participation at $T_{1}$.

The upper panel of Table VIII suggests that the causal link goes from identification with other farmers and participation in farmers' organizations to action preparedness, rather than the other way around. The correlations, $3 \mathrm{~s}$, and $R^{2}$ of the first equation are higher than those of the second equation, especially that of identification with other farmers. The lower panel suggests the opposite for protest participation: Participation seems to strengthen collective identity, rather than the reverse. Together with the findings in Tables II and III, the two panels of Table VIII suggest a neat causal pattern: Collective identity fosters action preparedness, action preparedness produces action participation, and action participation strengthens 
Table VIII. The Causal Link Between Identity and Collective Action Participation: Pearson $R \mathrm{~s}$ and Standardized $\beta \mathrm{s}$

\begin{tabular}{lccllr}
\hline & \multicolumn{2}{c}{ Preparedness at $T_{3}$} & & \multicolumn{2}{c}{ Preparedness at $T_{1}$} \\
& $r$ & $\beta$ & & $r$ & $\beta$ \\
\hline Identification at $T_{1}$ & .26 & .20 & Identification at $T_{3}$ & .12 & .06 \\
Identity organization at $T_{1}$ & .27 & .22 & Identity organization at $T_{3}$ & .20 & .18 \\
$R^{2}$ & & .11 & $R^{2}$ & & .04 \\
& Participation at $T_{3}$ & & \multicolumn{2}{c}{ Participation at $T_{1}$} \\
& $r$ & $\beta$ & & $r$ & $\beta$ \\
\hline Identification at $T_{1}$ & .11 & .03 & Identification at $T_{3}$ & .30 & .17 \\
Identity organization at $T_{1}$ & .28 & .27 & Identity organization at $T_{3}$ & .45 & .39 \\
$R^{2}$ & & .08 & $R^{2}$ & & .22 \\
\hline
\end{tabular}

collective identity. Indeed, collective identity, action preparedness, and action participation seem to function as a self-reinforcing mechanism.

\section{Discussion}

On the whole, our hypotheses were confirmed. A sense of collective identity indeed stimulates participation in collective action both in the Netherlands and in Galicia. Moreover, differences in group identification and participation in farmers' organizations could explain differences in protest participation between the two regions. Controlled for collective identity, differences in participation in farmers' protest appear to be the opposite of what they seemed: Galician farmers are more likely to take part in collective action than are their Dutch colleagues. It is only the circumstance that relatively few Galician farmers identify with other farmers and participate in farmers' organizations that leads fewer Galician farmers to take part in farmers' protest.

The longitudinal design of our study made it possible to actually test the causal relations implied by the theory. The results of our analyses suggest that identity processes stimulate action preparedness and that action preparedness generates action participation. Action participation, in turn, fosters someone's sense of identity. In a social psychological context, this causal sequence makes a lot of sense. Indeed, this finding combines the two theoretical links we encountered in the literature. It is noteworthy that the link between action preparedness and action participation serves as the connection between the two identity processes. This might explain why we find evidence of opposite causal direction in the literature, depending on whether it concerns the link with preparedness or with participation.

Obviously, identity processes can only explain part of the variance in action preparedness. After all, identity processes constitute only one of the two ways to participation, instrumentality being the other (Klandermans, 1997; Simon et al., 1998). The percentages of variance explained that we found with our simple 
indicators are somewhat lower than those reported by Stürmer (2000). But the gay movement is often mentioned as an example of an identity-oriented movement (Taylor \& Whittier, 1992), one that likely is more identity-oriented than the protest movement of farmers against governmental or European Union agricultural policy, which strikes us as predominantly instrumentally oriented. In any event, we would expect identity processes to play a more prominent role in the dynamics of participation in the gay movement than in those of farmers' protest. If this reasoning holds, one would expect identity processes to play a more prominent role than instrumentality in the context of participation in the gay movement. This is what Stürmer seems to have found. On the other hand, one would expect instrumentality processes to be more important in the context of participation in farmers' protest. Comparative research could provide an answer to this question.

Our findings seem to support the assumption that the affective and behavioral components of collective identity have different consequences for action participation. Indeed, the behavioral component has more influence on participation in collective action than does the affective component. We proposed that this is the case because involvement in an identity organization implies a higher level of politicization. The correlation we found in the Galician sample seems to support that line of thought, but we found no such correlation in the Dutch sample. An alternative explanation could be that the networks of the farmers' organizations have been involved in the organization of the protest, and that, therefore, people who were members of those organizations ran a greater chance of being targeted by mobilization attempts (Klandermans \& Oegema, 1987). That would, however, not explain why organizational membership had so much more effect on participation in Galicia. It could also be the case that behavior is best predicted by intention for that behavior (Fishbein \& Ajzen, 1975) and that all external factors affect behavior via intention. After all, the correlations of participation in an identity organization were not very high. Which of the three explanations will hold remains to be seen. Future research on the politicization of collective identity may provide the answer (Simon \& Klandermans, 2001).

Thus, the differences in protest participation between the Netherlands and Galicia are supposedly due to differences in identity processes, at least in part. Self-categorization theory would propose that the differences in identity processes we observed between the Netherlands and Galicia are brought about by contextual factors. We suggest that differences between agricultural policy in the Netherlands and Spain, differences between the agricultural sectors (organizational density, apolitical vs. politicized farmers' organizations) in the two countries, and less defined common interests and opponents are among the factors responsible for the observed differences in identity strength. Obviously, this is partially speculation. We have only two cases that differ on all kinds of factors. Despite these differences, identity processes could predict protest participation in the two countries in a similar way, and we could understand the differences in protest participation with the assumed functioning of identity processes; this suggests some generality and 
robustness of our findings. The fact that we were able to demonstrate the significance of identity processes even with our simple measures of collective identity is equally encouraging. We would assume that more sophisticated measures would have improved our results.

The causal patterns revealed by our analyses are fascinating. They suggest that strong identities foster preparedness to participate in collective action on behalf of the group. If such action is actually staged, the chances are high that preparedness will be transformed into action. Participation in turn reinforces the strength of identity. Hence, identity strength and movement participation may be recursive in nature. The social movement literature has offered this as a theoretical idea, but thus far has provided very little in terms of empirical support. The mainly experimental social psychological literature on social identity, on the other hand, in general fails to account for identity strength as a variable and therefore has little to offer for a theory of the development of strong identities. The development of such a theory is beyond the scope of this paper, but we think that we have contributed some building blocks. More research is needed to detail the role of identity processes in collective action on behalf of the group, but thus far the results are promising.

\section{AUTHOR'S ADDRESS}

Correspondence concerning this article should be sent to Bert Klandermans, Department of Social Psychology, Free University, van de Boechorststraat 1, 1081 BT Amsterdam, Netherlands. E-mail: pg.klandermans@ @sy.vu.nl

\section{REFERENCES}

Andrews, M. (1991). Lifetimes of commitment: Aging, politics, psychology. Cambridge: Cambridge University Press.

de Weerd, M. (1999). Sociaalpsychologische determinanten van boerenprotest: Collectieve actie frames, identiteit en effectiviteit. Unpublished doctoral dissertation, Vrije Universiteit.

de Weerd, M., \& Klandermans, B. (1999). Group identification and social protest: Farmers' protest in the Netherlands. European Journal of Social Psychology, 29, 1073-1095.

Drury, J., Reicher, S., \& Scott, C. (1999). Shifting boundaries of collective identity: Intergroup context and social category change in an anti-roads protest. Unpublished paper, University of Sussex, Brighton, U.K.

Ellemers, N. (1993). The influence of socio-structural variables on identity management strategies. In W. Stroebe \& M. Hewstone (Eds.), European review of social psychology (vol. 4, pp. 27-58). Chichester, UK: Wiley.

Fishbein, M., \& Ajzen, I. (1975). Belief, attitude, intention and behaviour. Reading, MA: Addison-Wesley.

Hornsey, M. J., \& Hogg, M. A. (in press). Intergroup similarity and subgroup relations: Some implications for assimilation. Personality and Social Psychology Bulletin.

Huddy, L. (2001). From social to political identity: A critical examination of social identity theory. Political Psychology, 22, 127-156. 
Kelly, C., \& Breinlinger, S. (1996). The social psychology of collective action. Basingstoke, UK: Taylor and Francis.

Klandermans, B. (1997). The social psychology of protest. Oxford: Blackwell.

Klandermans, B. (2000). Identity and protest: How group identification helps to overcome collective action dilemmas. In M. Van Vugt, M. Snyder, T. R. Tyler, \& A. Biel(Eds.), Cooperation in modern society: Promoting the welfare of communities, states, and organizations (pp. 162-183). London: Routledge.

Klandermans, B. \& Oegema, S. (1987). Potentials, networks, motivations and barriers: Steps toward participation in social movements. American Sociological Review, 52: 519-531.

Mummendey, A., Klink, A., Mielke, R., Wenzel, M., \& Blanz, M. (1999). Socio-structural characteristics of intergroup relations and identity management strategies: Results from a field study in East Germany. European Journal of Social Psychology, 29, 259-286.

Reicher, S. D. (1984). The St. Paul's riot: An explanation of the limits of crowd action in terms of a social identity model. European Journal of Social Psychology, 14, 1-21.

Reicher, S. D. (1996). The Battle of Westminster: Developing the social identity model of crowd behaviour in order to explain the initiation and development of collective conflict. European Journal of Social Psychology, 26, 115-134.

Simon, B. (1998). Individuals, groups, and social change: On the relationship between individual and collective self-interpretations and collective action. In C. Sedikides, J. Schopler, \& C. Insko (Eds.), Intergroup cognition and intergroup behavior (pp. 257-282). Mahwah, NJ: Erlbaum.

Simon, B. (1999). A place in the world: Self and social categorization. In T. R. Tyler, R. M. Kramer, \& O. P. John (Eds.), The psychology of the social self (pp. 47-69). Mahwah, NJ: Erlbaum.

Simon, B., \& Klandermans, B. (2001). Towards a social psychological analysis of politicized collective identity: Conceptualization, antecedents, and consequences. American Psychologist, 56, 319-331.

Simon, B., Loewy, M., Stürmer, S., Weber, U., Kampmeier, C., Freytag, P., Habig, C., \& Spahlinger, P. (1998). Collective identity and social movement participation. Journal of Personality and Social Psychology, 74, 646-658.

Stürmer, S. (2000). Soziale Bewegungsbeteiligung: Ein psychologisches Zwei-Wege Modell. Unpublished doctoral dissertation, University of Kiel.

Tajfel, H. (1981). Human groups and social categories. Studies in social psychology. London: Academic Press.

Tajfel, H., \& Turner, J. C. (1986). The social identity theory of intergroup behavior. In S. Worchel \& W. G. Austin (Eds.), The social psychology of intergroup relations (pp. 7-24). Monterey, CA: Brooks/Cole.

Taylor, V., \& Whittier, N. E. (1992). Collective identity in social movement communities: Lesbian feminist mobilization. In A. Morris \& C. Mueller (Eds.), Frontiers of social movement theory (pp. 104-130). New Haven, CT: Yale University Press.

Turner, J. C. (1999). Some current issues in research on social identity and self-categorization theories. In N. Ellemers, R. Spears, \& B. Doosje (Eds.), Social identity (pp. 6-34). Oxford: Blackwell.

Turner, J. C., Hogg, M. A., Oakes, P. J., Reicher, S. D., \& Wetherell, M. S. (Eds.) (1987). Rediscovering the social group. A self-categorization theory. Oxford: Blackwell. 